\title{
Estimação de Probabilidade de Perda de Dados em Redes Através de Modelagem Multifractal de Tráfego e Teoria de Muitas Fontes
}

\author{
Flávio Henrique Teles Vieira ${ }^{1}$ \\ Scheila Guedes Garcez ${ }^{2}$
}

\begin{abstract}
Resumo: Neste artigo, propomos uma abordagem para estimação da probabilidade de perda de bytes em enlaces de redes de computadores considerando propriedades multifractais dos fluxos de tráfego. Mais especificamente, deduzimos uma expressão matemática para o cálculo da probabilidade de perda para servidores com buffer finito alimentados com fluxos multifractais de tráfego. A abordagem proposta se baseia na teoria das muitas fontes e na modelagem multifractal de tráfego baseada em cascatas multiplicativas. Por fim, avaliamos a proposta de estimação de probabilidade de perda através de simulações computacionais utilizando séries de tráfego real, verificando assim sua eficiência como ferramenta relacionada à provisão de qualidade de serviço em redes de computadores.
\end{abstract}

\begin{abstract}
In this paper, we propose an approach to estimate the byte loss probability in computer network links considering multifractal properties of traffic flows. More specifically, we obtain a mathematical expression for the loss probability for finite buffer servers fed by multifractal traffic flows. The proposed approach is based on the Many Sources theory and on the multiplicative cascade based multifractal traffic modeling. Finally, we evaluate the proposed loss probability estimation approach through computer simulations using real traffic traces, verifying its efficiency as a tool related to quality of service provisioning for computer networks.
\end{abstract}

\section{Introdução}

Probabilidade de perda e atraso de pacotes são medidas de desempenho fundamentais associadas à qualidade de serviço (QoS) em redes de computadores. Vários estudos têm sido realizados com o intuito de caracterizar o tamanho médio da fila (backlog) e a distribuição do número de pacotes nos buffers dos roteadores da rede [1][2]. Dessa forma, é possível estabelecer limitantes para medidas de desempenho, tais como perda e atraso de pacotes ou

\footnotetext{
${ }^{1}$ Escola de Engenharia Elétrica e de Computação (EEEC) da Universidade Federal de Goiás (UFG)

Av. Universitária, n. 1488 - Quadra 86 - Bloco A - $3^{\circ}$ piso 74605-010 - Setor Leste Universitário - Goiânia - GO

\{flavio@eeec.ufg.br\}

${ }^{2}$ Departamento de Semicondutores, Instrumentos e Fotônica - Unicamp, Campinas, SP

\{garcez@dsif.fee.unicamp.br\}
} 
de bytes. $\mathrm{O}$ conhecimento destes limitantes permite garantir a qualidade de serviço requerida pelos fluxos de tráfego, para os quais vários modelos foram propostos [3] [4].

O modelo clássico de tráfego de Poisson foi proposto na década de 20 para análise de sistemas de telefonia e depois adaptado para a análise de fila em redes de pacotes [5]. Este modelo tem como vantagem o fato de ser analiticamente tratável, permitindo que expressões matemáticas sejam explicitamente derivadas para caracterização do desempenho de fila nos buffers. Mas com o advento das redes com suporte a vários serviços, a natureza do tráfego mudou drasticamente, exibindo características bem diferentes das preditas por modelos de Poisson e de Markov, como por exemplo, comportamento fractal [6].

As pesquisas sobre tráfego de redes encontraram-se com a teoria dos fractais a partir da publicação do trabalho de Leland, Taqqu, Willinger e Wilson [7]. Leland et al. constataram experimentalmente que o tráfego coletado na rede Ethernet do Bellcore Morristown Reaserch and Engineering Center exibia propriedades fractais tais como autossimilaridade. A característica de dependência de longa duração ou longa-dependência para uma série de tráfego implica em uma estrutura de correlação que decai mais lentamente do que a exponencial. Este decaimento lento da função de autocorrelação, relacionado também à autossimilaridade, foi observado no tráfego gerado por transmissão de vídeo a taxa variável [8][9][10], no tráfego em redes de longa distância (WAN-Wide Area Networks) e metropolitanas (MANMetropolitan Area Network) [11][12], tráfego Internet [13], dentre outros. Foi constatado que tais propriedades, com destaque para a dependência de longa duração, influenciam fortemente no desempenho e projeto de redes [4], não sendo adequadamente modeladas por processos estocásticos Markovianos.

Enquanto os modelos de tráfego de curta dependência são significativos por sua simplicidade, eles não capturam a dependência de longa duração presente nos traços reais de tráfego. Há muitos estudos que revelam a alta variabilidade do tráfego Internet, ou seja, o tráfego possui rajadas em uma gama de escalas de tempo em contraste da suposição de que rajadas de tráfego só existem em escalas curtas de tempo [7][12]. Foi mostrado que estas incidências de rajadas multiescalas têm um impacto significativo no desempenho das redes [7][12][14]. Os resultados publicados em [14] mostram que o conhecimento das características do tráfego em múltiplas escalas ajuda a melhorar a eficiência dos mecanismos de controle de tráfego.

Outras propriedades do tráfego de redes foram também descobertas apontando para um comportamento do tráfego mais complexo do que se supunham os modelos monofractais [15]. Os resultados em [14] indicam que o desempenho de fila depende mais da variabilidade do tráfego em certas escalas de tempo do que do valor do parâmetro de Hurst $H$, que mede o grau de autossimilaridade de um processo. Realmente, verificou-se que diferentes processos com longa dependência possuindo o mesmo valor do parâmetro de Hurst podem gerar comportamentos de fila sensivelmente diferentes [16]. A origem dessas propriedades, consi- 
deradas presentes em pequenas escalas de tempo, é atribuída à ação dos protocolos predominantes nas redes em questão, e dos mecanismos fim-a-fim de controle de congestionamento existentes na Internet atual, que determinam o comportamento do fluxo de informações entre diferentes camadas na hierarquia de protocolos TCP/IP [17]. Tais constatações motivaram a busca por modelos de tráfego mais abrangentes, que possibilitassem uma descrição mais completa do tráfego de redes.

Investigações envolvendo tráfego TCP/IP [18][17] constataram que essas diferentes propriedades e comportamentos do tráfego são convenientemente descritos utilizando-se a análise multifractal. Para muitos processos de tráfego de rede, seus gráficos de energia em escala dos coeficientes wavelet ou os de variância-tempo normalmente não têm comportamento linear [19]. Muitos destes processos apresentam uma combinação de comportamentos fractais, com parâmetro de Hurst variado em diferentes pequenas escalas de tempo, ou seja, são multifractais [20]. De fato, o desempenho de fila depende das irregularidades do tráfego em escalas de tempo pequenas devido à dinâmica complexa das redes de dados [16].

Em resumo, propomos neste artigo uma abordagem para a estimação de probabilidade de perda de bytes utilizando a teoria de muitas fontes e modelagem multifractal de tráfego baseada em cascatas multiplicativas. Comparamos também o desempenho de nossa proposta com o trabalho descrito em [2], que também envolve fluxos de tráfego multifractal.

\section{Estimação de Probabilidade de Perda para Tráfego Multifractal}

Sejam $A(t)$ o processo de chegada de pacotes acumulados em um servidor no intervalo de tempo contínuo $[0, t)$ com incrementos estacionários, $C$ a capacidade do servidor e $I(t)$, o processo de chegada de dados à entrada da rede para chegadas no intervalo de tempo $[0, t)$, dado por

$$
I(t)=A(t)-C t .
$$

O processo correspondente ao tamanho de fila $W(t)$ em tempo contínuo é representado pelas seguintes equações:

$$
W(0)=0 \quad e \quad W(t)=\sup _{s \leq t}\{I(t)-I(s)\}
$$

Para que a fila seja estável é preciso que $E[A(t)-C t]<0$. A equação de Lindley é usada para calcular o tamanho da fila de um enlace. Segundo a equação de Lindley, o tamanho da fila depende da taxa de chegada de tráfego no instante $t$ e da taxa de serviço do enlace. Dessa forma, a distribuição em regime permanente do processo de tamanho de fila $Q$ 
pode ser expressa como uma generalização da equação de Lindley da seguinte forma [21]:

$$
Q \stackrel{d}{=} \sup _{t \geq 0}\{A(t)-C t\}
$$

onde $\stackrel{d}{=}$ denota igualdade em distribuição.

Poucos trabalhos tratam de problemas de fila cujo tráfego de entrada $A(t)$ tem um comportamento em escala mais complexo, como é o caso de enlaces com tráfego multifractal de entrada [22][1] [23]. Para muitos modelos de tráfego, a análise assintótica do comportamento de fila $Q$ é a única forma disponível. A aproximação assintótica geralmente fornece uma visão bastante simplificada do tráfego de redes e geralmente não se aplica a buffer finito. Para o caso de tráfego multifractal de entrada, as análises de fila tradicionais e clássicas como M/M/1, M/G/1 e G/G/1 não ajudam muito. Neste caso, os comportamentos e leis de potência de diferentes ordens das estatísticas dos fluxos de tráfego em várias escalas são aspectos mais importantes e relevantes.

Dentre os estudos de estimação assintótica de probabilidade de perda para tráfego multifractal, Gao et al. simularam filas com processos multiplicativos multifractais de entrada, mas não apresentando resultados analíticos [22][24]. Enquanto, S. Molnár et al. propuseram uma equação aproximada para o comportamento assintótico de cauda de fila, ou seja, eles determinaram uma equação para a probabilidade de cauda de perda em um servidor tendo como entrada um processo multifractal. Em particular, quando o tráfego de entrada é monofractal, esta probabilidade de perda assintótica tem um decaimento de Weibull, o que é consistente com outros resultados [3][1].

Com relação a tráfego multifractal de entrada, podemos citar o trabalho de Ribeiro et al. [2], que desenvolveram uma análise de fila multiescala para modelos multifractais baseados em cascata via um método não-assintótico, válida para qualquer tamanho de buffer. Esta aproximação nomeada de Análise de Fila Multiescala (Multiscale Queueing) incorpora as distribuições dos dados de tráfego em múltiplas resoluções temporais (não apenas as estatísticas de segunda ordem) [2]. Considere o processo aleatório discreto $L_{i}$ representando a carga (volume) de tráfego que entra um servidor com buffer infinito e capacidade de serviço constante $c$. Supondo também que $Q_{i}$ represente o tamanho da fila no instante de tempo $i$. Denotemos por $K_{r}$, o tráfego agregado que chega entre os instantes 0 a $r$, ou seja

$$
K_{r}=\sum_{i=0}^{r} L_{i} .
$$

O processo $K_{r}$ refere-se aos dados de tráfego na escala de tempo $r$. Modelos baseados em cascata multiplicativa provêem fórmulas explícitas e simples para $K_{r}$ em escalas de tempo 
Estimação de Probabilidade de Perda de Dados em Redes Através de Modelagem Multifractal de Tráfego e Teoria de Muitas Fontes

diádicas, ou seja, $r=2^{n}(n=1,2, \ldots, \infty)$. A Análise de Fila Multiescala mostra que a probabilidade de perda $P[Q>b]$ pode ser estimada pela seguinte equação [2]:

$$
P[Q>b] \approx 1-\prod_{i=0}^{n} P\left[K_{2^{n-i}}<b+c 2^{n-i}\right]
$$

onde $b$ é o tamanho do buffer e $c$ é a capacidade (taxa de transmissão) do servidor.

Na próxima subseção tratamos sobre o modelo multifractal de tráfego proposto no presente trabalho.

\subsection{Modelagem Multifractal baseada em Cascata Multiplicativa}

A cascata binomial é o método mais simples de se obter um processo multifractal, consistindo de um procedimento iterativo no intervalo compacto [0,1]. Sejam $m_{0}$ e $m_{1}$ (multiplicadores da cascata) dois números positivos cuja soma é 1 . No estágio $k=0$ da cascata, obtemos a medida inicial $\mu_{0}$ do processo com valor aleatório entre $[0,1]$. No estágio $k=1$, a medida $\mu_{1}$ distribui massa, sendo, $m_{0}$ no subintervalo [0,1/2] e massa igual a $m_{1} \mathrm{em}[1 / 2$, 1]. Em $k=2$, o intervalo [0,1/2] é subdividido em [0,1/4] e [1/4,1/2] e o mesmo acontece com intervalo [1/2,1], obtendo-se [25]:

$$
\begin{array}{rc}
\mu_{2}[0,1 / 4]=m_{0} m_{0} \quad \mu_{2}[1 / 4,1 / 2]=m_{0} m_{1}, \\
\mu_{2}[1 / 2,3 / 4]=m_{1} m_{0} \quad \mu_{2}[3 / 4,1]=m_{1} m_{1} .
\end{array}
$$

Com a repetição desse processo podemos gerar a seqüência de medidas $\mu_{k}$, que converge então para o processo multifractal $\mu$.

Processos multifractais são definidos por leis de escala e momentos estatísticos dos processos de incrementos em intervalos de tempo finitos conforme definição a seguir.

Definição 1 Um processo estocástico $X(t)$ é multifractal se satisfaz a equação:

$$
E\left(|X(t)|^{q}\right)=c(q) t^{\tau(q)+1}
$$

onde $t \in T$ e $q \in Q, T$ e $Q$ são intervalos na reta real, $\tau(q)$ e $c(q)$ são funções com domínio $Q$. Normalmente, assume-se que $T$ e $Q$ têm comprimentos positivos, e que $0 \in T,[0,1] \subseteq Q$.

A Definição 1 descreve o comportamento multifractal em termos de momentos estatísticos onde $\tau(q)$ e $c(q)$ são conhecidos como a função de escala e o fator de momento de um processo multifractal, respectivamente. 
Estimação de Probabilidade de Perda de Dados em Redes Através de Modelagem Multifractal de Tráfego e Teoria de Muitas Fontes

Sabe-se que as propriedades multifractais dos dados reais de tráfego são caracterizadas por suas correspondentes função de escala $\tau(q)$ e fator de momento $c(q)$ [26]. Então, um modelo multifractal geral deve capturar estas duas propriedades multifractais [1]. Segundo os autores em [26], isto pode ser obtido pelo produto de uma cascata e uma variável aleatória i.i.d. positiva $Y$, obtendo um processo multifractal $X(t)$. Dessa forma, o modelo multifractal resultante pode ser visto como o produto da taxa de pico do fluxo $Y$, pela medida de rajada $\mu\left(\Delta t_{N}\right)$ na escala de tempo aplicada $\Delta t_{N}$. Para este modelo, a função de escala $\tau(q)$ pode ser precisamente modelada assumindo que $R$ é uma variável aleatória em [0,1] com distribuição beta simétrica $\operatorname{Beta}(\alpha, \alpha) \operatorname{com} \alpha>0$ [1]. Assim, a função $\tau_{0}(q):=\tau(q)+1$ relacionada à função de escala $\tau(q)$, pode ser explicitamente escrita como

$$
\tau_{0}(q)=\log _{2} \frac{\Gamma(\alpha) \Gamma(2 \alpha+q)}{\Gamma(2 \alpha) \Gamma(\alpha+q)},
$$

onde $\Gamma($.$) corresponde à função Gama. Já a variável Y$ pode ser modelada como uma variável aleatória lognormal definida pelos parâmetros $\rho$ e $\gamma$ e portanto, possuindo momento $E\left(Y^{q}\right)=$ $e^{\rho q+\gamma^{2} q^{2} / 2}[26]$.

Foi demonstrado que o parâmetro de escala global (parâmetro de Hurst) para um processo multifractal $X(t)$ como o descrito nesta seção, pode ser calculado pela seguinte equação [27]:

$$
H=1-\frac{\log _{2}\left(\frac{\alpha+1}{\alpha+1 / 2}\right)}{2} .
$$

onde $\alpha$ é o parâmetro da distribuição $\operatorname{Beta}(\alpha, \alpha)$ utilizada para modelar a função de escala $\tau(q)$.

A equação (8) será útil para o desenvolvimento de nossa proposta, assim como a média do processo $X(t)$ baseado em cascata multiplicativa, dada por [26]:

$$
E(X(t))=e^{\rho+\gamma^{2} / 2}
$$

onde $\rho$ e $\gamma$ são parâmetros da variável $Y$ do modelo multifractal considerado que se refere ao produto de uma cascata e uma variável aleatória i.i.d. positiva $Y$.

\section{Probabilidade de Perda Assintótica pela Teoria das Muitas Fontes}

Em geral, a quantidade disponível de recursos da rede depende não apenas das propriedades estatísticas e dos requisitos de qualidade de serviço de uma fonte, mas também das propriedades estatísticas de outros fluxos de tráfego que estão sendo multiplexados em conjunto e das características do enlace (capacidade do enlace e tamanho do buffer). Em 
[28][29], é mostrado que a banda efetiva de uma fonte depende do ponto de operação ('operating point') do enlace através dos parâmetros de espaço $s$ e de tempo $t$, que dependem dos recursos do enlace e das propriedades estatísticas do tráfego multiplexado. A banda efetiva pode ser estimada usando a teoria assintótica de muitas fontes ao invés de se considerar o limite assintótico de buffers grandes, obtendo assim uma estimativa menos conservadora (banda menor mas que atende à probabilidade de perda estipulada) para buffers menores [30]. Este resultado ocorre porque a teoria assintótica de buffer grande não leva em consideração o possível ganho de multiplexação quando fontes de tráfego independentes são multiplexadas. Na teoria assintótica de Muitas Fontes, estuda-se o decaimento da probabilidade de perda $P(Q>b)$ com o aumento do número de entradas independentes para cada roteador, enquanto o tamanho do buffer por entrada e a taxa de serviço por entrada permanecem fixos. Nesta seção, determinamos o ponto de operação do enlace considerando um modelo multifractal baseado em cascata para o tráfego e a Teoria Assintótica de Muitas Fontes.

Seja $\alpha_{n}(s, t)$ uma estimativa da banda efetiva $\alpha(s, t)$ para uma série de tráfego de tamanho $T=n t$. Deseja-se determinar o ponto de operação, ou seja, os valores de tempo $t \mathrm{e}$ do parâmetro de espaço $s$ para os quais a banda efetiva se relaciona com a probabilidade de transbordo assintótica [31]. Esta banda efetiva é relacionada com a probabilidade de transbordo do buffer $\Psi \approx \log P\left(Q_{n}>b\right)$ sob o regime assintótico de 'muitas fontes' através da fórmula [32]:

$$
\Psi=\inf _{t \geq 0} \sup _{s \geq 0}\left((b+c t) s-N_{s} s t \alpha(s, t)\right),
$$

onde $c$ é a capacidade do enlace, $b$ é o tamanho do buffer e $N_{s}$ é o número de fontes de entrada com banda efetiva igual a $\alpha(s, t)$. O par de variáveis $\left(s^{*}, t^{*}\right)$ com o qual a otimização inf sup na equação (10) é atendida, corresponde ao 'ponto de operação' do enlace.

Seja a função $\Lambda_{n}(s, t)$ uma estimativa de $\Lambda(s, t)=E\left(e^{s X}\right)$, a função geradora de momento de um processo $X(t)$. Pode-se afirmar que o par de variáveis $\left(s_{n}^{*}, t_{n}^{*}\right)$ é um estimador consistente de $\left(s^{*}, t^{*}\right)$, dado pelas seguintes equações [33]:

$$
\begin{gathered}
b+c t_{n}^{*}=\frac{(\partial / \partial s) \Lambda_{n}\left(s_{n}^{*}, t_{n}^{*}\right)}{\Lambda_{n}\left(s_{n}^{*}, t_{n}^{*}\right)} \\
c s_{n}^{*}=\frac{(\partial / \partial t) \Lambda_{n}\left(s_{n}^{*}, t_{n}^{*}\right)}{\Lambda_{n}\left(s_{n}^{*}, t_{n}^{*}\right)}
\end{gathered}
$$

Quando um modelo de tráfego é adotado para o tráfego de chegada, uma aproximação paramétrica pode ser empregada para o cálculo da função geradora de momento. Faremos uma aproximação para o cálculo da função geradora de momento de forma a obter uma expressão analítica para o 'ponto de operação'. Sabe-se que o modelo fBm (fractional Brownian motion) descreve bem tráfego agregado, ou seja, tráfego composto pela agregação de várias 
Estimação de Probabilidade de Perda de Dados em Redes Através de Modelagem Multifractal de Tráfego e Teoria de Muitas Fontes

fontes [3]. Como a análise apresentada nesta seção envolve teoricamente muitas fontes, assumiremos que $\Lambda_{n}(s, t)$ das equações (11) e (12) é a função geradora de momento de um processo agregado. Assim, tem-se o seguinte para função geradora de momento [3]:

$$
\Lambda_{n}(s, t)=\exp \left(\mu t s+\frac{t^{2 H} \sigma^{2} s^{2}}{2}\right),
$$

onde $\mu$ é a média, $\sigma^{2}$ é a variância do processo em questão. Resolvendo o sistema de equações (11) e (12), encontramos as seguintes equações para o 'ponto de operação' do enlace:

$$
t^{*}=\frac{H b}{(c-\mu)(1-H)}
$$

$\mathrm{e}$

$$
s^{*}=\frac{b\left(t^{*}\right)^{-2 H}}{\sigma^{2}(1-H)}
$$

onde $H$ pode ser calculado pela equação (8).

Dessa forma, uma expressão analítica para a estimação da probabilidade de perda de $J$ fluxos de tráfego em um servidor pode ser obtida utilizando a equação (10), isto é:

$$
\log P\left(Q_{n}>b\right) \approx\left(\left(b+c t^{*}\right) s^{*}-s^{*} t^{*} \sum_{j=1}^{J} \alpha_{j}(s, t)\right),
$$

onde o ponto de operação $\left(s^{*}, t^{*}\right)$ é dado pelas equações (14) e (15).

Note que é demonstrado na literatura que a aproximação através da Análise Assintótica de Muitas Fontes pode ser aplicada igualmente a qualquer modelo de tráfego tradicional (por exemplo, modelos Markovianos) e modelos com longa dependência [31].

\section{Probabilidade de Perda Não-Assintótica para Tráfego Multifractal}

A cauda da distribuição do tamanho da fila, ou seja, a estimação assintótica da probabilidade de perda em um sistema de fila com buffer infinito, tem sido bastante estudada [34][35][36]; enquanto, há um número reduzido de trabalhos que tratam diretamente da probabilidade de perda em sistemas com buffer finito [37][38][39]. Na literatura, a taxa de perda de pacote (probabilidade de perda) $P_{l}(x)$ é freqüentemente aproximada pela probabilidade de cauda (probabilidade de transbordo) $P(Q>x)$, que de fato, fornece um limitante superior para a probabilidade de perda, mas muitas vezes sem muita precisão [40][41]. Estudos realizados comprovam que tanto para vários modelos de tráfego, como para séries de tráfego reais, esta estimativa representa realmente um limitante superior bastante aproximado [42][43]. 
Estimação de Probabilidade de Perda de Dados em Redes Através de Modelagem Multifractal de Tráfego e Teoria de Muitas Fontes

Seja um servidor com taxa constante $c$, um fluído de entrada $\lambda_{n}$, e os processos $Q_{n}$ e $\hat{Q}_{n}$ denotando o tamanho da fila para buffer finito e infinito no instante de tempo $n$, respectivamente. Supõe-se que $\lambda_{n}$ seja estacionário e ergódico e que $E\left(\lambda_{n}\right)<c$. No cálculo de probabilidade de perda, considera-se que $Q_{n}$ e $\hat{Q}_{n}$ sejam estacionários e ergódicos. A probabilidade de perda $P_{l}(x)$ para um buffer de tamanho $x$ é definida como a razão entre a quantia de fluido de tráfego perdido pela quantia de fluido de entrada como [44]:

$$
P_{l}(x)=\lim _{N \rightarrow \infty} \frac{\sum_{k=1}^{N} \max \left(Q_{k-1}+\lambda_{k}-c-x, 0\right)}{\sum_{k=1}^{N} \lambda_{k}} .
$$

Já a probabilidade de cauda é definida como o tempo gasto pelo fluido de tráfego no buffer de tamanho infinito, acima de um nível $x$, dividido pelo tempo total de observação e pode ser expressa como [44]:

$$
P(Q>x)=\lim _{N \rightarrow \infty} \frac{1}{N} \sum_{k=1}^{N} I\left(\hat{Q}_{k}>x\right),
$$

onde se $A$ é uma hipótese verdadeira, $I(A)=1$; do contrário, $I(A)=0$.

Pode-se estimar a taxa de perda de bytes (probabilidade de perda de bytes) $P_{l}(x)$ em um buffer finito através da cauda da distribuição do tamanho de fila (probabilidade de cauda ou probabilidade de transbordo) $P(Q>X)$ para processos multifractais de entrada. Devido à estrutura multiplicativa dos processos multifractais, a distribuição destes processos é aproximadamente lognormal. Este resultado pode ser constatado na prática principalmente para tráfego real em pequenas escalas de tempo [14] [17]. Aproveitando este fato, a análise de fila pode ser simplificada, gerando a seguinte proposição.

Proposição 1: Seja um processo de tráfego $X(t)$ cujo parâmetro de escala global $H$ é dado por (8). A probabilidade de perda em um servidor com capacidade $c$ e buffer finito $b$ para o processo $X(t)$ pode ser expressa como

$$
P_{l}(x)=e^{\left(x s^{*}\right)-\left(\rho+\gamma^{2} / 2\right)} \int_{c}^{\infty}(r-c) \frac{1}{r \theta \sqrt{2 \pi}} e^{\frac{-(\ln (r)-\varpi)^{2}}{2 \theta^{2}}} d r,
$$

sendo:

$$
s^{*}=\frac{b\left(t^{*}\right)^{-2 H}}{\sigma^{2}(1-H)}
$$

e

$$
t^{*}=\frac{H b}{(c-\mu)(1-H)} \text {. }
$$


Estimação de Probabilidade de Perda de Dados em Redes Através de Modelagem Multifractal de Tráfego e Teoria de Muitas Fontes

onde os parâmetros $\varpi$ e $\theta$ são relacionados com a média $\mu$ e a variância $\sigma^{2}$ do processo $X(t)$ pelas seguintes equações:

$$
\begin{gathered}
\varpi=\ln \mu-\frac{1}{2} \ln \left(\frac{\sigma^{2}}{\mu^{2}}+1\right), \\
\theta=\sqrt{\ln \left(\frac{\sigma^{2}}{\mu^{2}}+1\right) .}
\end{gathered}
$$

sendo que $\alpha$ é o parâmetro da distribuição $\operatorname{Beta}(\alpha, \alpha)$ utilizada para modelar a função de escala $\tau(q)$, e $\rho$ e $\gamma$ são parâmetros da variável $Y$ do modelo multifractal referente ao produto de uma cascata e uma variável aleatória i.i.d. positiva $Y$.

Demonstração da Proposição 1: Tendo estimativas da probabilidade assintótica de cauda $P(Q>x)$ e da probabilidade de perda $P_{l}(a)$ para um buffer de tamanho a qualquer, a probabilidade de perda $P_{l}(x)$ pode ser calculada por [44]:

$$
P_{l}(x)=\frac{P_{l}(a)}{P(Q>a)} P(Q>x) .
$$

Convém utilizar a equação (24) para $a=0$ porque a probabilidade de perda $P_{l}(0)$ é mais fácil de ser calculada. Para o cálculo de $P(Q>x)$ e $P(Q>0)$, pode-se usar a equação (16) que é um resultado assintótico derivado da teoria de muitas fontes.

Seja $\lambda_{n}$ a taxa do tráfego de entrada, assim a probabilidade de perda $P_{l}(x=0)$ pode ser calculada como [44]:

$$
P_{l}(0)=\frac{E\left\{\max \left\{\left(\lambda_{n}-c\right), 0\right\}\right\}}{E\left\{\lambda_{n}\right\}} .
$$

Supondo agora que o processo $\lambda_{n}$ seja um processo multifractal baseado em cascata multiplicava com média $\mu$ e variância $\sigma^{2}$, respectivamente. Sendo o modelo baseado em cascata multiplicativa, o mesmo apresenta distribuição de probabilidade lognormal [25]. Dessa forma, a equação (25) pode ser reescrita como

$$
P_{l}(0)=\frac{1}{e^{\rho+\gamma^{2} / 2}} \int_{c}^{\infty}(r-c) \frac{1}{r \theta \sqrt{2 \pi}} e^{\frac{-(\ln (r)-\varpi)^{2}}{2 \theta^{2}}} d r
$$

onde os parâmetros $\varpi$ e $\theta$ são relacionados com a média $\mu$ e a variância $\sigma^{2}$ do processo $X(t)$ pelas seguintes equações: 
Estimação de Probabilidade de Perda de Dados em Redes Através de Modelagem Multifractal de Tráfego e Teoria de Muitas Fontes

$$
\begin{gathered}
\varpi=\ln \mu-\frac{1}{2} \ln \left(\frac{\sigma^{2}}{\mu^{2}}+1\right), \\
\theta=\sqrt{\ln \left(\frac{\sigma^{2}}{\mu^{2}}+1\right)} .
\end{gathered}
$$

A teoria assintótica de muitas fontes provê o resultado necessário para os cálculos de $P(Q>x)$ e $P(Q>0)$ através da equação (16) e a partir da aplicação da equação (26) em (24), obtém-se a probabilidade de perda enunciada nesta proposição:

$$
P_{l}(x)=e^{\left(x s^{*}\right)-\left(\rho+\gamma^{2} / 2\right)} \int_{c}^{\infty}(r-c) \frac{1}{r \theta \sqrt{2 \pi}} e^{\frac{-(\ln (r)-\varpi)^{2}}{2 \theta^{2}}} d r .
$$

Note que $s^{*}$ é um dos parâmetros do ponto de operação $\left(s^{*}, t^{*}\right)$ apresentado, que é calculado utilizando-se as equações (20) e (21). Assim, demonstramos a equação (19).

Para validar a equação proposta para a probabilidade de perda de bytes em um enlace, realizamos simulações com várias séries de tráfego reais. $\mathrm{O}$ ambiente de simulação utilizado foi o Matlab. Considerou-se nas simulações um enlace composto de um buffer para armazenamento dos dados de entrada e de um servidor com uma determinada taxa de transmissão (capacidade do servidor). A Figura 1 compara as probabilidades de perda de bytes em termos do tamanho do buffer obtidas com a equação (19), pela Análise de Fila Multiescala [2] e através da simulação de um enlace com um servidor alimentado pela série de tráfego dec-pkt-2 na escala de tempo de $512 \mathrm{~ms}$ [45]. A capacidade do servidor foi ajustada para 120 porcento da taxa média. O mesmo é apresentado para a série de tráfego dec-pkt-3 na Figura 2 na escala de tempo de $512 \mathrm{~ms}$, escala na qual esta série de tráfego apresenta comportamento multifractal 2. Já a série dec-pkt-2 tende a ter um comportamento monofractal, ou seja, uma relação mais linear entre a função de escala $\tau(q)$ e $q$ [46][47].

A análise das Figuras 1 e 2 revela que estimativas mais precisas para a probabilidade de perda são obtidas através da nossa proposta do que a Análise de Fila Multiescala. Observase que o comportamento de ambos os modelos vai se tornando mais impreciso a medida que o tamanho do buffer aumenta, por exemplo, para tamanhos acima de $10 \times 10^{5}$ bytes. No entanto, mesmo para tamanhos de buffer o decaimento da probabilidade de perda para a equação proposta se mantém mais próximo do real do que o método de Análise de Fila Multiescala. Note que, assim como a equação de probabilidade de perda proposta, a Análise de Fila Multiescala estima a probabilidade de perda $P_{l}(x)$ e não a probabilidade de cauda; este é o principal motivo de sua escolha para comparação. 
Estimação de Probabilidade de Perda de Dados em Redes Através de Modelagem Multifractal de Tráfego e Teoria de Muitas Fontes

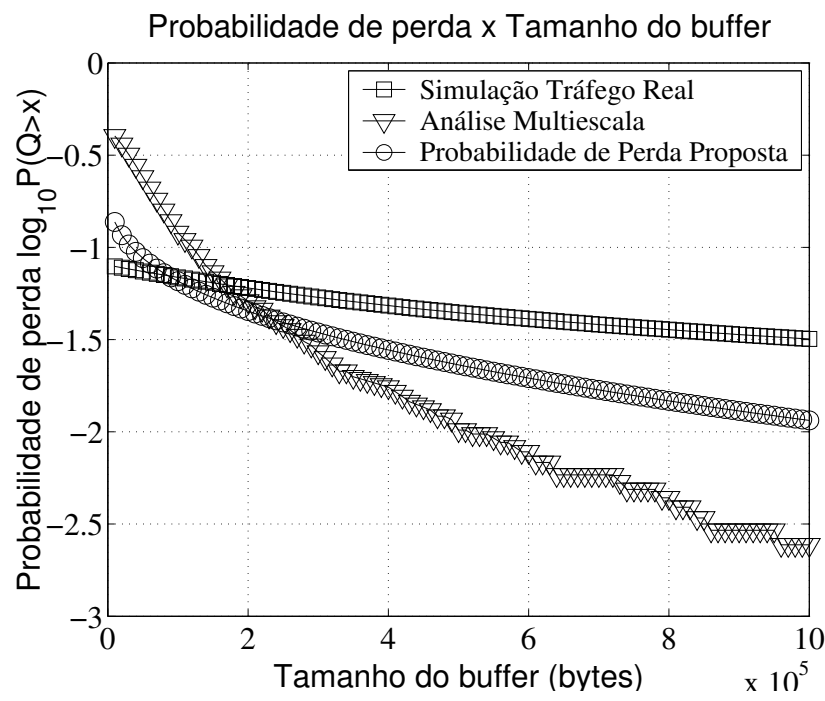

Figura 1. Probabilidade de perda de bytes para a série de tráfego dec-pkt-2

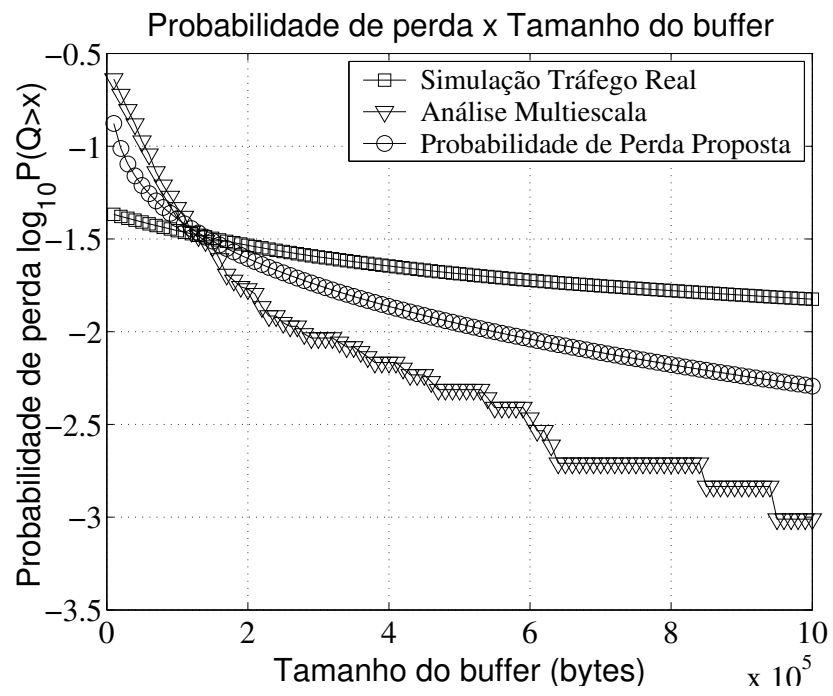

Figura 2. Probabilidade de perda de bytes para a série de tráfego dec-pkt-3 
Estimação de Probabilidade de Perda de Dados em Redes Através de Modelagem Multifractal de Tráfego e Teoria de Muitas Fontes

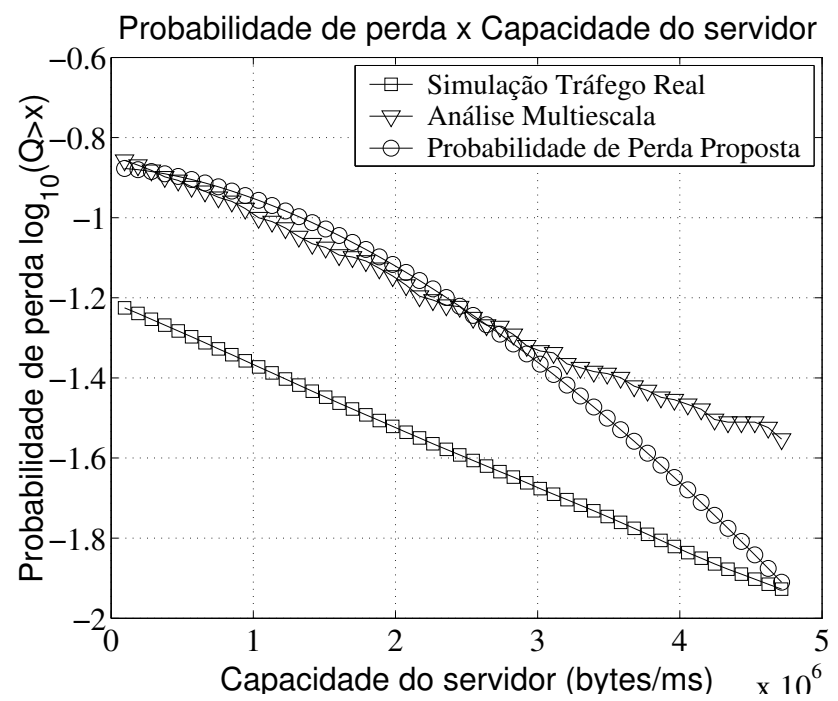

Figura 3. Probabilidade de perda de bytes x Capacidade do servidor para a série de tráfego dec-pkt-3

Prosseguindo a análise de probabilidade de perda de bytes, com o intuito de verificar o decaimento da probabilidade de perda em termos da capacidade do servidor, fixamos o tamanho do buffer em $1,4 \times 10^{5}$ bytes. Este tamanho do buffer foi escolhido pois com este valor os dois métodos baseados em processo multifractais e a simulação apresentaram desempenho próximos em relação à perda para a série de tráfego dec-pkt-3, como pode ser visto pela Figura 2. A Figura 3 mostra o comportamento da nossa abordagem de cálculo de probabilidade de perda comparada à Análise de Fila Multiescala e à real probabilidade de perda estimada através de simulação com a série de tráfego dec-pkt-3, em função da capacidade do servidor. Observa-se que a equação (29) provê resultados mais realistas para os valores de capacidade do servidor considerados, apresentando uma taxa de decaimento mais próxima da probabilidade de perda real do que o método de fila multiescala. Pode-se notar que a medida que a capacidade do servidor é aumentada, os resultados da equação proposta se tornam mais precisos. Mesmo para valores menores do que $3 \times 10^{6}$ bytes, os valores do método proposto são bem próximos aos dos da Análise de Fila Multiescala. Nesta faixa de valores, ambos os modelos poderiam prever uma taxa de perda maior do que realmente ela é, segundo os resultados apresentados. 


\section{Conclusão}

O tráfego de redes possui características que são descritas mais adequadamente por modelos multifractais, principalmente em pequenas escalas de tempo [18] [2]. Sabe-se que algumas das propriedades dos processos multifractais têm impacto direto no desempenho das redes [16] [14]. Com isso, métodos mais eficientes de alocação de recursos podem ser obtidos ao se considerar tais modelos.

Poucos trabalhos tratam de problemas de fila cujo tráfego de entrada tem um comportamento em escala mais complexo, como é o caso de enlaces com tráfego multifractal de entrada [22][1]. Para muitos modelos de tráfego, a análise assintótica do comportamento de fila $Q$ é a única forma disponível. Neste artigo, propomos uma análise não assintótica para o comportamento de fila. Assim, deduzimos uma expressão matemática para a probabilidade de perda em um servidor de fila com buffer finito assumindo um modelo multifractal para o tráfego de entrada. Para tal, encontramos os valores ótimos para os parâmetros de operação do enlace $(s, t)$ utilizando uma equação para o parâmetro de escala global para um processo multifractal. A equação proposta exigiu que algoritmos para estimação dos parâmetros $\alpha, \rho$ e $\gamma$ do modelo multifractal considerado, fossem implementados.

A taxa de perda de pacotes ou bytes é um dos principais parâmetros para se avaliar a qualidade de serviço oferecida a um fluxo de tráfego. Neste estudo, o comportamento de fila, descrito pela probabilidade de perda, foi caracterizado analiticamente através de parâmetros multifractais do tráfego. As simulações considerando séries de tráfego real revelaram que a equação de probabilidade de perda proposta é mais precisa do que o método de Análise de Fila Multiescala. O método proposto assim como a Análise de Fila Multiescala obtém resultados mais próximos dos das simulações para capacidades de servidor maiores do que $3 \times 10^{6}$ e para tamanhos de buffer menores do que algo em torno de $10 \times 10^{5}$.

A estimação da probabilidade de perda feita de forma eficiente pode servir como ferramenta para se estimar e controlar os mecanismos de um servidor de rede, tais como como a ocupação do buffer e a alocação de taxas de transmissão. Neste sentido, quanto mais precisa for a estimação do comportamento dos fluxos que trafegam pela rede, mais apropriado será o serviço oferecido ao usuário. Por outro lado, se a abordagem utilizada não for capaz de representar bem ou oferecer mecanismos de controle para o tráfego real, o desempenho real da rede pode ser subestimado ou superestimado. A abordagem proposta de estimação de taxa de perda pode ser utilizada também para se dimensionar adequadamente a rede, prevendo por exemplo o tamanho do buffer, a taxa de transmissão do enlace ou o número de usuários adequados para que determinado requisito de taxa de perda seja atendido. Portanto, os resultados obtidos com a análise não-assintótica proposta para a estimação da probabilidade de perda de pacotes, a tornam uma alternativa analítica promissora no projeto e análise de desempenho de redes. 
Estimação de Probabilidade de Perda de Dados em Redes Através de Modelagem Multifractal de Tráfego e Teoria de Muitas Fontes

\section{Agradecimentos}

Os autores agradecem ao CNPQ pelo apoio a esta pesquisa e ao Prof. Lee Luan Ling pelos comentários sobre o presente trabalho.

\section{Referências}

[1] S. Molnár, T. D. Dang, and I. Maricza, "On the queue tail asymptotics for general multifractal traffic,” in Em Proc., IFIP Networking'02, Pisa, Italia, Maio 2002.

[2] V. J. Ribeiro, R. H. Riedi, M. S. Crouse, and R. G. Baraniuk, "Multiscale queueing analysis of long-range dependent traffic," in IEEE INFOCOM, Tel Aviv, Israel, Março 2000, pp. 1026-1035.

[3] I. Norros, "A storage model with self-similar input," Queueing Systems, vol. 16, pp. 387-396, 1994.

[4] K. Park and W. Willinger, Self-similar Network Traffic and Performance Evaluation. New York: John Wiley and Sons, 2000.

[5] L. Kleinrock, Queueing systems: VolI: Theory. John Wiley, Inc., 1975.

[6] P. H. P. Carvalho, P. S. Barreto, and C. Silva, "Uma metodologia de planejamento e roteamento adaptativo em redes multimídia," Revista IEEE América Latina, vol. 7, pp. 673-680, 2009.

[7] W. E. Leland, M. S. Taqqu, W. Willinger, and D. V. Wilson, "On the self-similar nature of ethernet traffic (extended version)," IEEE/ACM Transactions on Networking, vol. 2, pp. 1-15, 1994.

[8] J. Beran, R. Sherman, M. Taqqu, and W. Willinger, "Variable-bit-rate video traffic and long-range dependence,” IEEE Trans. Commun., vol. 43, pp. 1566-1579, 1995.

[9] M. W. Garret and W. Willinger, "Analysis, modeling and generation of self-similar vbr vide traffic," in Proceedings of ACM Sigcomm, 1994, pp. 269-280.

[10] F. H. P. Fitzek and M. Reisslein, "MPEG-4 and H.263 video traces for network performance evaluation," IEEE Trans. on Networking, vol. 15, no. 6, pp. 40-54, Nov/Dez 2001.

[11] R. G. Addie, M. Zukerman, and T. D. Neame, "Fractal traffic: Measurements, modeling and performance evaluation," in Proceedings of INFOCOM, Abril 1995, pp. 977-984. 
Estimação de Probabilidade de Perda de Dados em Redes Através de Modelagem Multifractal de Tráfego e Teoria de Muitas Fontes

[12] V. Paxson and S. Floyd, "Wide-area traffic: The failure of poisson modeling," IEEE/ACM Transactions on Networking, vol. 3, no. 3, pp. 226-244, 1995.

[13] M. E. Crovella and A. Bestavros, "Self-similarity in world wide web traffic - evidence and possible causes," in Proceedings of ACM Sigmetrics, 1996, pp. 160-169.

[14] A. Erramilli, O. Narayan, and W. Willinger, "Experimental queueing analysis with longrange dependent packet traffic," IEEE/ACM Trans. on Net., vol. 4, no. 2, Abril 1996.

[15] F. H. T. Vieira and L.L.Ling, "Adaptive wavelet-based multifractal model applied to the effective bandwidth estimation of network traffic flows," IET Communications, vol. 3, pp. 906-920, 2009.

[16] M. Grossglauser and J. C. Bolot, "On the relevance of long-range dependence in network traffic," IEEE/ACM Transactions on Networking, vol. 7, no. 5, pp. 629-640, Outubro 1999.

[17] A. Feldmann, A. C. Gilbert, and W.Willinger, "Data networks as cascades: Investigating the multifractal nature of internet WAN traffic." Vancouver: ACM/SIGCOMM'98, 1998, pp. 25-38.

[18] R. H. Riedi and J. L. Véhel, “Tcp traffic is multifractal: a numerical study," INRIA Research report, Tech. Rep. 3129, 1997.

[19] Y. Xu, "A network traffic model based on fractal," in International Conference on Wireless Communications, Networking and Mobile Computing, Shanghai, Setembro 2007, pp. $1921-1924$.

[20] Q. Li and D. Mills, "Investigating the scaling behavior, crossover," in Proc. of Globecom, 1999, pp. 1843-1852.

[21] D. A. Rolls, G. Michailidis, and F. Hernández-Campos, "Queueing analysis of network traiffc: methodology and visualization tools," Computer Networks, vol. 48, pp. 447473, Janeiro 2005.

[22] J. Gao and I. Rubin, "Multifractal analysis and modeling of long range-dependent traffic," in Proceedings of ICC'99, Junho 1999.

[23] F. G. C. Rocha, F. H. T. Vieira, and J. A. S. Jr, "A multifractal based approach for loss probability estimation for ofdm/tdma based systems," in 13th International Symposium on Wireless Personal Multimedia Communications, Recife PE, 2010.

[24] J. Gao and I. Rubin, "Superposition of multiplicative multifractal traffic streams," in In Proceedings of ICC 2000, Junho 2000. 
Estimação de Probabilidade de Perda de Dados em Redes Através de Modelagem Multifractal de Tráfego e Teoria de Muitas Fontes

[25] B. B. Mandelbrot, A. Fisher, and L. Calvet, “A multifractal model of asset return," Yale University, Tech. Rep., 1997.

[26] T. D. Dang., S. Molnár, and I. Maricza, "Capturing the complete characteristics of multifractal network traffic,” in GLOBECOM 2002, Taipei, Taiwan, Novembro 2002.

[27] F. H. T. Vieira and L. L. Ling, "Limitantes de desempenho de fila para tráfego multifractal de redes," Infocomp- Journal of Computer Science, vol. 6, no. 4, pp. 100-109, Dezembro 2007.

[28] F. Kelly, Notes on effective bandwidths, ser. In Stochastic Networks: Oxford University Press, 1996.

[29] C. Courcoubetis, F. P. Kelly, and R. Weber, "Measurement-based usage charges in communications networks," Statistical Laboratory, University of Cambridge," 1997-19, 1997.

[30] G. L. Choudhury, D. M. Lucantoni, and W. Whitt, "On the effectiveness of effective bandwidths for admission control in ATM networks," in In Proc. of the 14th International Teletraffic Congress (ITC-14). North Holland: Elsevier Science B. V., 1994, pp. 411-420.

[31] C. Courcoubetis, V. A. Siris, and G. D. Stamoulis, "Application of the many sources asymptotic and effective bandwidths to traffic engineering," Telecommunication Systems, vol. 12, pp. 167-191, 1999.

[32] C. Courcoubetis and R. Weber, "Buffer overflow asymptotics for a switch handling many traffic sources," Journal of Applied Probability, vol. 33, pp. 886-903, 1996.

[33] L. Aspirot, P. Belzarena, P. Bermolen, A. Ferragut, G. Perera, and M. Simon, "Quality of service parameters and link operating point estimation based on effective bandwidths," Performance Evaluation, vol. 59, no. Issues 2-3, pp. 103-120, Fevereiro 2005.

[34] C. Chang, "Stability, queue length and delay of deterministic and stochastic queueing networks," IEEE Trans. Automat. Contr., vol. 39, pp. 913-931, Maio 1994.

[35] P. W. Glynn and W. Whitt, "Logarithmic asymptotics for steady-state tail probabilities in a single-server queue,” J. Appl. Probab. A (special issue), vol. 31, pp. 131-156, 1994.

[36] R. G. Addie and M. Zukerman, "An approximation for performance evaluation of stationary single server queues," IEEE Trans. Commun., vol. 42, pp. 3150-3160, Dezembro 1994. 
Estimação de Probabilidade de Perda de Dados em Redes Através de Modelagem Multifractal de Tráfego e Teoria de Muitas Fontes

[37] L. Likhanov and R. R. Mazumdar, "Cell loss asymptotics for buffers fed with a large number of independent stationary processes," in Proc. of IEEE INFOCOM'98, San Francisco USA, Abril 1998.

[38] A. Baiocchi, N. Melazzi, M. Listani, A. Roveri, and R. Winkler, "Loss performance analysis of an ATM multiplexer loaded with high-speed on-off sources," IEEE J. Select. Areas Commun., vol. 9, pp. 388-393, Abril 1991.

[39] N. Shroff and M. Schwartz, "Improved loss calculations at an ATM multiplexer," Sch. Elec. Comput. Eng., Purdue Univ., West Lafayette,, Tech. Rep., 1998.

[40] M. Krunz and A. M. Ramasamy, "The correlation structure for a class of scene-based video models and its impact on the dimensioning of video buffers," IEEE Trans. Multimedia, vol. 2, pp. 27-36, 2000.

[41] A. Gyorgy and T. Borsos, "Estimates on the packet loss ratio via queue tail probabilities," in GLOBECOM'01, vol. 4, Novembro 2001, pp. 2407-2411.

[42] N. G. Duffield, J. T. Lewis, N. O'Connell, R. Russel, and F. Tomey, "Entropy of ATM traffic streams: a tool for estimating QoS parameters," IEEE Journal on Selected Areas in Commun., vol. 13, no. 6, pp. 981-990, Agosto 1995.

[43] F. P. Kelly, "Effective bandwidth at multi-class queues," Queue Syst., vol. 9, pp. 5-16, 1991.

[44] H. S. Kim and N. B. Shroff, "Loss probability calculations and asymptotic analysis for finite buffer multiplexers," IEEE/ACM Trans. on Networking, vol. 9, no. 6, Dezembro 2001.

[45] A. Erramilli, O. Narayan, A. Neidhardt, and I. Saniee, "Performance impacts of multiscaling in wide area TCP/IP traffic," in Proc. Infocom, Março 2000.

[46] F. H. T. Vieira and L. L. Ling, "Multifractal traffic modeling using a multiplicative cascade with generalized multiplier distributions," in International Conference on Communications -ICC'06, Istanbul, Turquia, 12 a 15 de Junho 2006.

[47] — "Queueing analysis for multifractal traffic through network calculus and global scaling parameter," in International Telecommunications Simposium - ITS, Fortaleza CE, Setembro 2006. 